\title{
Conservative Treatment of Acute Spontaneous Spinal Epidural Hematoma
}

\author{
Peter A. Pahapill and Stephen P. Lownie
}

\begin{abstract}
Background: In cases of acute spontaneous spinal epidural hematoma producing neurological deficits, emergency surgical evacuation is the standard treatment. Methods: Such a case is presented in which complete resolution of neurological deficits occurred without surgical intervention. Results: This is the fifth reported case of complete recovery in a patient managed conservatively. In most reports, significant and sustained neurological recovery had occurred within 12 hours of impairment of walking. Conclusion: In cases of acute spontaneous spinal epidural hematoma in which neurological deterioration is followed by early and sustained recovery, non-operative therapy may be considered.
\end{abstract}

\begin{abstract}
RÉSUMÉ: Traitement conservateur de l'hématome épidural spontané aigu. Introduction: L'évacuation chirurgicale d'urgence est le traitement standard dans les cas d'hématome épidural spinal spontanés aigus provoquant des déficits neurologiques. Méthodes: Nous présentons un cas chez qui une résolution complète des déficits neurologiques a été observée sans intervention chirurgicale. Résultats: Il s'agit du cinquième cas rapporté d'une guérison complète chez un patient traité de façon conservatrice. Dans la plupart des cas rapportés, une récupération neurologique significative et soutenue était survenue dans les 12 heures de l'atteinte de la marche. Conclusion: Dans les cas aigus d'hématome épidural spinal spontané aigu chez qui la détérioration neurologique est suivie d'une récupération précoce et soutenue, un traitement conservateur peut être considéré.
\end{abstract}

Can. J. Neurol. Sci. 1998; 25: 159-163

Spinal epidural hematoma (SEH) is an unusual cause of acute spinal cord compression that without treatment will usually result in a permanent neurological deficit. ${ }^{1-5}$ In about $50 \%$ of cases, SEHs are related to a known precipitating factor, such as spinal trauma; anticoagulant therapy; hemorrhagic diatheses such as hemophilia; arteriovenous malformation; spinal cord neoplasm; or to an iatrogenic origin, such as epidural anesthesia. "Spontaneous" SEHs have been defined as those occurring in the absence of the above conditions. The standard therapy for SEH is prompt surgical evacuation of the hematoma which will often lead to significant neurological recovery. ${ }^{1-5}$ Conservative treatment of SEH has been considered in situations where surgery may be contraindicated (e.g. patients on anticoagulants ${ }^{6}$ or with hemophilia ${ }^{7}$ ). We recently encountered a patient with an acute spontaneous SEH producing significant neurological deficits. The patient recovered without surgical intervention. Only four such cases have been previously reported. ${ }^{8-11}$ The role of nonsurgical treatment in acute spontaneous SEH is discussed.

\section{Case Report}

This 30-year-old man awoke suddenly with severe left sided chest pain. The pain radiated anteriorly to the right and then around to his back in a belt-like distribution. The pain was described as knife-like in quality. Although the pain gradually diminished over 72 hours, he did seek medical attention because of a residual "belt-like pressure feeling" around his upper chest, made worse by coughing. A presumptive diagnosis of pneumonia was made and he was given a prescription for antibiotics. Later the same day he noticed the sudden onset of weakness, numbness and tingling of his legs. He almost fell down but managed to hold himself up with his arms. He subsequently noticed difficulty in initiating both voiding and defecation. The next day he noticed that the numbness had ascended to his upper chest. He returned to the local hospital because of persistent leg weakness. Upon admis. sion to the local hospital, he required a walker for ambulation and almost required bladder catheterization on one occasion. Over the next 24 hours his leg strength improved to the point that he did not require a walker for ambulation and his bladder and bowel function returned to normal.

The patient's past health was remarkable for non-displaced fractures of the vertebral bodies of $T_{4}$ and $T_{5}$ at age 17 after a fall. There were no neurological symptoms at the time. Neither he nor his family had any history of bleeding disorders. He was on no medications. A CT myelogram performed the next day was consistent with a thoracic epidural hematoma (not shown). The patient was then transferred to a neurosurgical centre.

Upon transfer, general physical examination was normal with no evidence of systemic illness or vascular or hematological disease. On neurological examination, there was Grade 4 weakness of the hip and knee flexors. Tone was normal. Sensory testing demonstrated a decreased appreciation of light touch and pin prick from $T_{3}$ to $T_{8}$ on the right and from $T_{5}$ to $T_{8}$ on the left. Deep tendon reflexes were normal and symmetrical. The left toe was upgoing. He was able to walk without assistance but his gait was slow and wide-based.

Laboratory examination including prothrombin time, partial thromboplastin time, bleeding time, factor VIII assay and liver function tests were unremarkable.

Magnetic resonance imaging (MRI) of the spine showed a thoracic epidural hematoma of moderate size (Figure l). In light of the patient's improving condition a conservative approach was taken. A spinal

From the Department of Clinical Neurological Sciences, University Campus, London Health Sciences Centre, University of Western Ontario, London

RECEIVED JULY 31, 1997. ACCEPTED IN FINAL, FORM OCTOBER 16, 1997.

Reprint requests to: S. P. Lownie, Department of Clinical Neurological Sciences, University Campus, London Health Sciences Centre, 339 Windermere Road, London, Ontario, N6A 5A5, Canada 

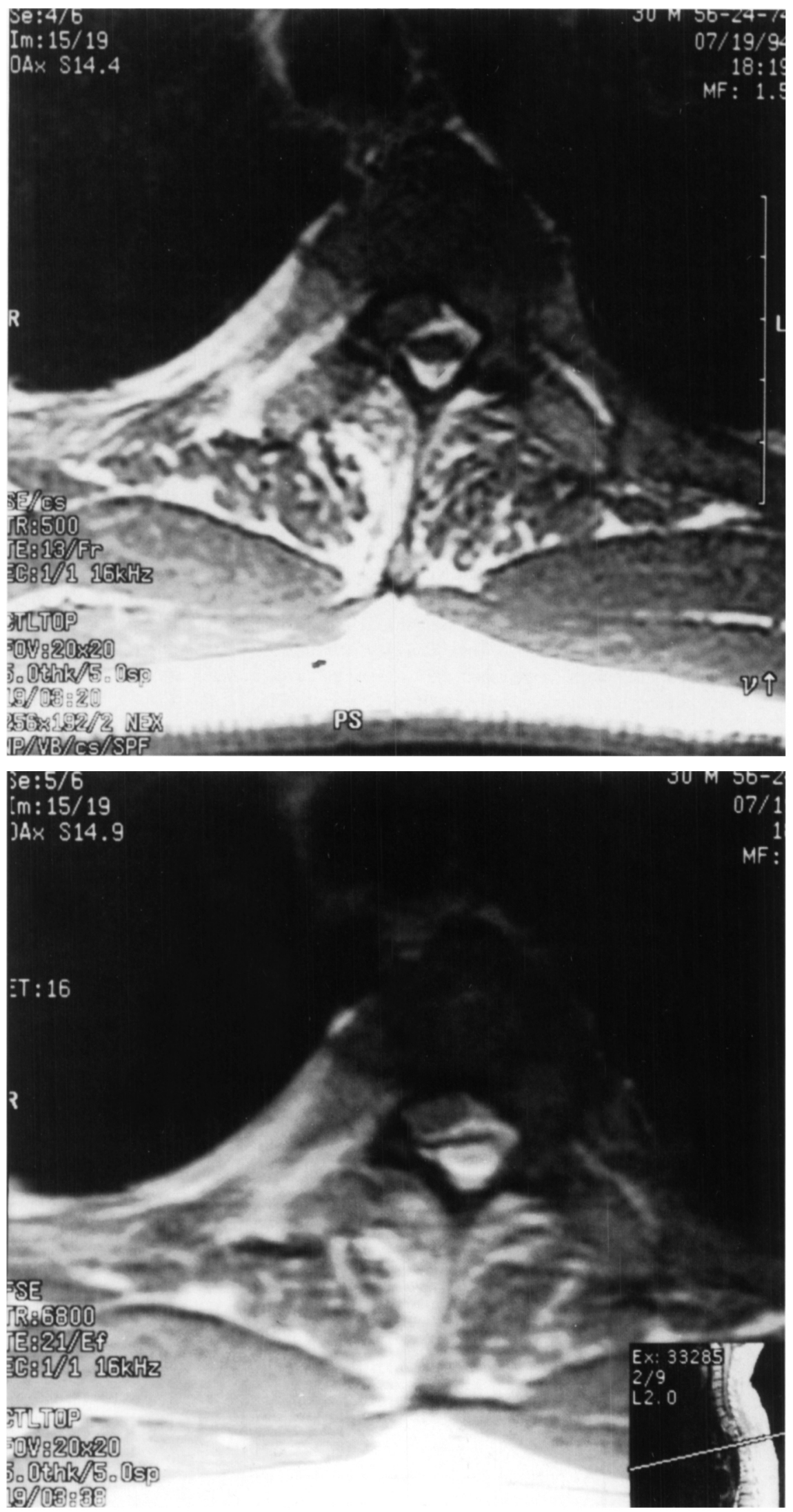

Figure 1: Magnetic resonance images (MRI) performed on the day of hospital admission: Axial $T_{1}-$ weighted $(A)$ and $T_{2}-$ weighted $(B)$ images at the $T_{3}-T_{4}$ level. A mixed isointense hyperintense spinal epidural mass is seen posterolateral to the spinal cord. The findings are consistent with a thoracic epidural hematoma producing moderate compression of the spinal cord. 


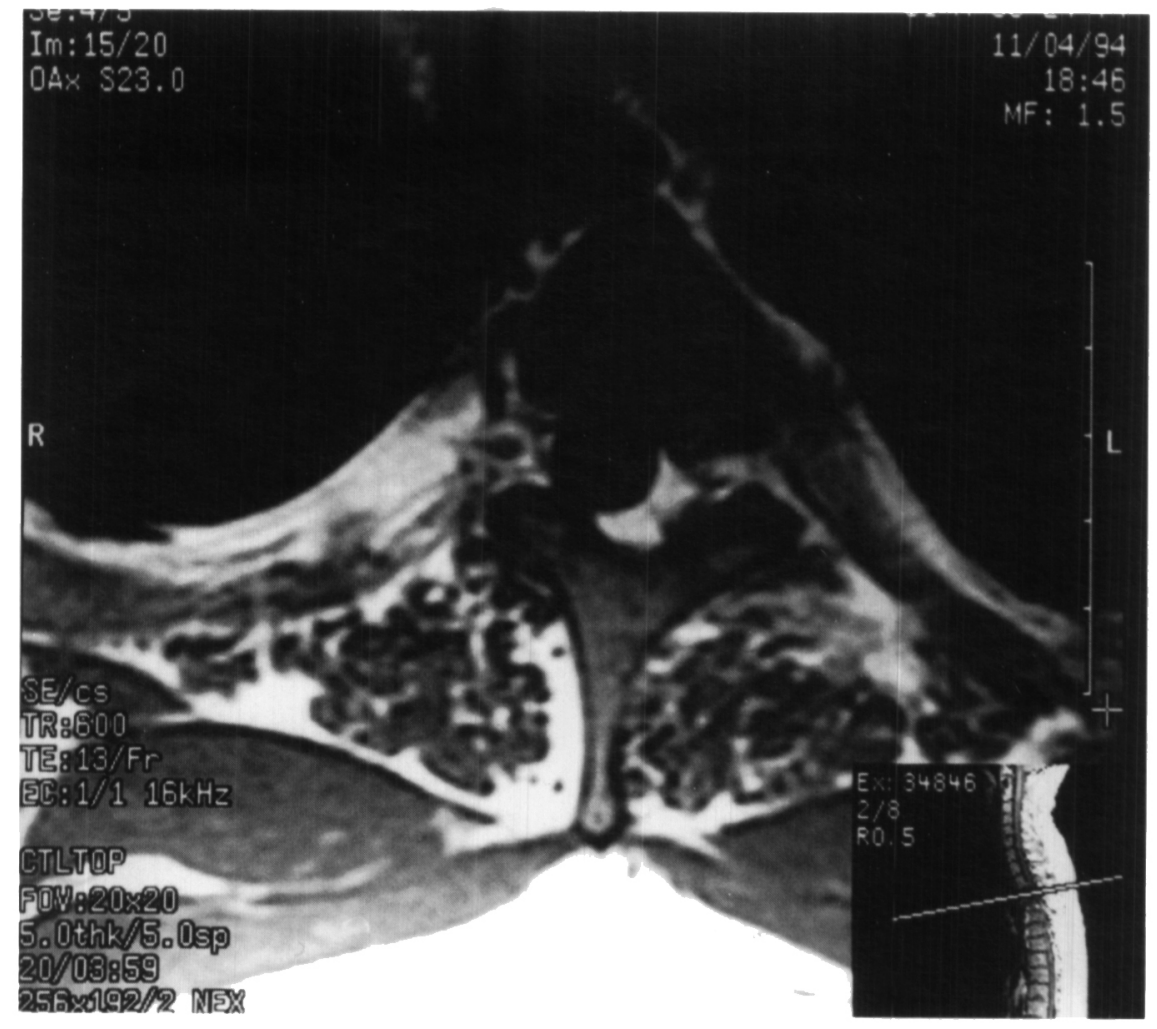

Figure 2: Axial $T_{1}$ - weighted MRI image at the $T_{3}-T_{4}$ level two months after initial presentation showing near complete spontaneous resolution of the epidural hematoma (there is still a persistent small extradural lesion with minimal displacement of the cord).

angiogram was done and was normal. Over the following week the patient recovered full strength in the lower extremities although he had mild persistent decrease in pin prick and light touch sensation in the mid-thoracic region. The patient was then released and seen in followup two months later at which time there were no complaints. Neurological examination revealed no abnormalities. Repeat MRI studies showed no residual abnormalities (Figure 2 ).

\section{Discussion}

Spontaneous recovery from an acute spontaneous SEH with resolution of neurological symptoms is rare. The Table summarizes the four previous such cases as well as the case presented. (Three other cases have been reported but have been excluded from this study because of lack of significant neurological deficits other than pain or lack of detailed history ${ }^{12,14}$ )

Patient Profile Of the five patients, three were male and two were female. The average age at diagnosis was 58 years and ranged from 30 to 76 years of age. The SEH occurred in two patients on acetylsalicylic acid, $, 8,10$ in two patients with hypertension $^{9,11}$ and one occurred in a patient with a remote history of a thoracic spine fracture (the case presented in this paper). Three of the five hematomas were triggered by non-traumatic events that would be apt to increase the pressure in the spinal venous system. One patient had been straining on the toilet, another had been bending forward and another was doing calisthenics (see Table).

Clinical Presentation Invariably, the first symptom was intense local pain in the spine. Simultaneously or shortly thereafter four patients noted a radicular component to the pain. The pain remained interscapular in one patient. ${ }^{10}$ Evidence of myelopathy occurred within minutes in two patients, within an hour in one, within 24 to 48 hours in another and between 48 and 72 hours in the case presented. In three cases bladder disturbance occurred. In one patient the sensory and motor deficits were complete. In another case the motor deficit was complete but sensory deficit was incomplete. In the other three cases the sensory and motor deficits were incomplete.

Radiological Investigation Myelography alone was performed in one patient. ${ }^{9}$ A CT scan alone was done in one patient, ${ }^{8}$ while CT myelography was performed in three patients. ${ }^{10,11}$ Magnetic resonance imaging was performed in two patients. ${ }^{10}$ Myelography showed incomplete block in three patients ${ }^{9,10}$ and no evidence of block in one patient." Spinal angiography was performed in two patients, both with negative results. ${ }^{11}$

Location Three of the five cases involved the thoracic region ${ }^{9.11}$. one case involved the cervicothoracic region ${ }^{10}$ and one was predominantly in the cervical region. ${ }^{8}$

Treatment There were no contraindications to surgery in the five cases. One patient with hypertension and diabetes had three episodes of complete paraplegia and anesthesia. Each lasted 30 to 120 minutes over a course of five hours with complete clinical recovery occurring shortly after hospital admission." As such no surgery was performed. In the other four patients significant and sustained neurological recovery occurred between 3 and 12 hours after the initial onset of myelopathic symptoms. The specific details of the motor examination were not available. In the case presented, muscle power had recovered to at least grade 4 by the time of clinical presentation. All of the patients eventually had full recovery of neurological function as early as 12 hours or as late as 3 months after onset. 
Table 1: Summary of Previous Cases of Acute Spontaneous Spinal Epidural Hematoma Treated Conservatively with Recovery

\begin{tabular}{|c|c|c|c|c|c|}
\hline Ref & Age/Sex & $\begin{array}{l}\text { Predisposing/ } \\
\text { Precipitating Factors }\end{array}$ & History & $\begin{array}{l}\text { Neurological Deficits at Initial Hospital } \\
\text { Presentation }\end{array}$ & Outcome \\
\hline 11 & $51 / \mathrm{M}$ & Straining; Hypertension & $\begin{array}{l}\text { Fluctuating paraplegia- } \\
\& \text { anesthesia }\end{array}$ & $\begin{array}{l}\text { At } 2 \text { hours: incomplete motor } \& \\
\text { urinary retention }\end{array}$ & $\begin{array}{l}\text { Full recovery at } \\
12 \text { hours }\end{array}$ \\
\hline 9 & $68 / F$ & Bending forward & $\begin{array}{l}\text { Radicular pain; } \\
\text { paraplegia at } 27 \text { hours }\end{array}$ & $\begin{array}{l}\text { At } 27 \text { hours: complete motor } \\
\& \text { sensory; At } 34 \text { hours: } \\
\text { incomplete motor \& sensory }\end{array}$ & $\begin{array}{l}\text { Continued } \\
\text { improvement; full } \\
\text { recovery at } 3 \text { days }\end{array}$ \\
\hline 8 & $63 / \mathrm{F}$ & Aspirin & $\begin{array}{l}\text { Radicular pain \& } \\
\text { hemiparesis }\end{array}$ & $\begin{array}{l}\text { At } 12 \text { hours: incomplete } \\
\text { motor \& sensory and } \\
\text { urinary retention }\end{array}$ & $\begin{array}{l}\text { Continued } \\
\text { improvement; full } \\
\text { recovery at } 3 \\
\text { months }\end{array}$ \\
\hline 10 & $76 \mathrm{M}$ & $\begin{array}{l}\text { Exercise; } \\
\text { Aspirin }\end{array}$ & $\begin{array}{l}\text { Intrascapular pain; } \\
\text { Paralysis at } 1 \text { hour }\end{array}$ & $\begin{array}{l}\text { At } 0 \text { hours: complete motor } \\
\& \text { incomplete sensory } \\
\text { At } 2 \text { hours: incomplete } \\
\text { motor and sensory }\end{array}$ & $\begin{array}{l}\text { Significant } \\
\text { improvement at } 5 \\
\text { hours }\end{array}$ \\
\hline- & $30 / \mathrm{M}$ & $\begin{array}{l}\text { Remote } T_{4} / T_{5} \\
\text { fractures }\end{array}$ & $\begin{array}{l}\text { Radicular pain; } \\
\text { unable to walk at } \\
72 \text { hrs }\end{array}$ & $\begin{array}{l}\text { At } 4 \text { days: incomplete } \\
\text { motor; walking with walker }\end{array}$ & $\begin{array}{l}\text { Full recovery at } \\
2 \text { months }\end{array}$ \\
\hline
\end{tabular}

Surgical versus Conservative Management The standard treatment for SEH is prompt surgical evacuation..$^{1-5,15}$ A delay of greater than 36 hours from the onset of inability to walk until the time of surgical decompression has been associated with a poor outcome. ${ }^{5}$ In a literature review of acute spontaneous SEH, Markham et al. reported that of 8 patients treated conservatively (from the years 1869 to 1958), all died within 9 days, whereas of 41 patients undergoing surgical decompression, 10 died, 16 fully recovered and only $6 \mathrm{did}$ not improve ${ }^{4}$ More recent reviews have shown improved operative results. ${ }^{1,2,5}$ Best results have been with incomplete lesions, although the mortality rates have not been insignificant. However, since the mortality with conservative treatment has been so devastating, prompt surgical evacuation has been the standard. The only detailed reports of conservative treatment of acute spontaneous SEHs in the English literature since the review by Markham et al. are those summarized in the Table.

In a literature review of post-traumatic SEHs, Foo and Rossier ${ }^{15}$ reported that of 7 patients treated conservatively, all died, whereas of 31 patients undergoing surgical decompression, 8 died and 21 improved. Since that review, there have been three reports of conservative management of post-traumatic SEHs presenting with incomplete neurological deficits. ${ }^{16-18}$ In all three cases, the trauma was relatively mild with no evidence of spinal fracture. All three patients recovered fully with significant and sustained improvement in the neurological function within hours of the injury. Emery et al. described a patient whose spinal epidural hematoma was caused by an arteriovenous malformation. ${ }^{19}$ Dramatic reduction of the patient's pain and paralysis occurred during myelography, a full day before the arteriovenous malformation was removed at surgery.

Data on the outcome of conservative treatment of SEH in hemophiliacs is limited, although recent reports have been encouraging. ${ }^{720,21}$ These results coupled with the poor outcomes of such patients following laminectomy ${ }^{7}$ support a more conservative approach in this group. There have been several reports of spontaneous recovery of neurological deficits after SEH in patients on anticoagulant therapy. ${ }^{622-25}$ Thus, for these "non-surgical" patients, the outcome of conservative therapy need not be considered hopeless in terms of neurologic recovery.

The cases summarized in the Table illustrate that spontaneous recovery from an acute spontaneous SEH can occur, and is independent of clinical factors such as age, sex, medications, level and possible etiology of hematoma and the severity of neurological deficits. The one characteristic that is consistent in this series is the rapidity of neurological recovery which occurred within 12 hours of the onset of significant myelopathic symptoms. Thus if rapid neurological deterioration is followed by early and sustained recovery, non-operative therapy may be appropriate.

\section{Conclusions}

The treatment of choice for a spinal epidural hematoma has traditionally been emergent surgical evacuation. ${ }^{1-5,15}$ There has been no defined role for conservative treatment. We have described a patient who developed leg weakness secondary to an acute spontaneous thoracic epidural hematoma. The symptoms resolved spontaneously and this was correlated with resolution of the epidural hematoma on follow-up MRI studies. Spontaneous recovery from acute spontaneous spinal epidural hematoma has been described rarely and our case is the fifth example of such an event.

In previous reports, the spontaneous resolution of an acute spinal epidural hematoma has occurred in patients with a broad range of background characteristics (age, sex, etiology and localization of hematoma, temporal progression of symptoms, severity of symptoms). However, in all cases there was rapid resolution of myelopathic symptoms within hours of their onset. We propose a possible role for conservative treatment in patients who demonstrate a significant and sustained reversal of myelopathic symptoms. In general, emergent surgical evacuation is the 
standard treatment. However, in certain cases in which neurological deterioration is followed by early and sustained recovery, non-operative therapy may be considered.

\section{REFERENCES}

1. Bruyn GW, Bosma NJ: Spinal extradural haematoma, in Vinken PJ, Bruyn GW (eds): Handbook of Clinical Neurology, vol 26. Amsterdam: North-Holland 1976; 1-30.

2. Foo D, Rossier AB: Preoperative neurological status in predicting surgical outcome of spinal epidural hematomas: Surg Neurol 1981; 15: 389-401.

3. Jelinger K: Traumatic vascular disease of the spinal cord, $I n$ : Vinken PJ, Bruyn GW, eds. Handbook of Clinical Neurology, vol 12: Vascular diseases of the nervous system: Part II. Amsterdam: L North-Holland, 1972: 556-630.

4. Markham JW, Lynge HN, Stahlman GEB: The syndrome of spontaneous spinal epidural hematoma. Report of three cases. J Neurosurg 1967; 26: 334-342.

5. McQuarrie IG: Recovery from paraplegia caused by spontaneous spinal epidural hematoma. Neurology 1978; 28: 224-228.

6. Harik SI, Raichle MR, Reis DJ: Spontaneously remitting spinal epidural hematoma in a patient on anticoagulants. $\mathrm{N}$ Engl $\mathbf{J}$ Med 1971; 284: 1355-1357.

7. Harvie A, Lowe GDO, Forbes CD et al: Intraspinal bleeding in haemophilia: successful treatment with factor VIII concentrate. J Neurol Neurosurg Psychiatry 1977; 40: 1220-1223.

8. Anderson TJ, Donaldson IM: Spontaneous resolution of cervical spinal epidural haematoma. Postgrad Med J 1989; 65: 488-490.

9. Brawn LA, Bergval UEG, Davies-Jones GAB: Spontaneous spinal epidural haematoma with spontaneous resolution. Postgrad Med J 1986; 62: 885-887.

10. Clarke DB, Bertrand G, Tampieri D: Spontaneous spinal epidural hematoma causing paraplegia: resolution and recovery without surgical decompression. Neurosurgery 1992; 30: 108-111.

11. Hernandez D, Vinuela F, Feasby TE: Recurrent paraplegia with total recovery from spontaneous spinal epidural haematoma. Ann Neurol 1982; 11: 623-624.
12. Kingery WS, Seibel M, Date ES, et al: The natural resolution of a lumbar spontaneous epidural hematoma and associated radiculopathy. Spine 1993; 19: 67-69.

13. Matsumae M, Shimoda M, Shibuya N, et al: Spontaneous cervical epidural hematoma. Surg Neurol 1987; 28: 381-384.

14. Saito S, Katsube H, Kobayashi Y: Spinal epidural haematoma with spontaneous recovery demonstrated by magnetic resonance imaging. Spine 1993; 19: 483-486.

15. Foo D, Rossier AB: Post-traumatic spinal epidural hematoma. Neurosurgery $1982 ; 11: 25-32$.

16. Crabbe DCG, Mendelow AD, Pharoh $P$, et al: Cervical spinal extradural haematoma causing a transient Brown-Sequard syndrome. J Neurol Neurosurgery Psychiatry 1992; 55: 239.

17. Laissy JP, Milon P, Freger P, et al: Cervical epidural hematomas: CT diagnosis in two cases that resolved spontaneously. Am J Neuroradiol 1991; 11: 394-396.

18. Pan G, Kulkarni M, MacDougall DJ, et al: Traumatic epidural hematoma of the cervical spine: diagnosis with magnetic resonance imaging. J Neurosurg 1988; 68: 798-801.

19. Emery DJ, Cochrane DD: Spontaneous remission of paralysis due to spinal extradural hematoma: case report. Neurosurgery 1988; 23: 762-764.

20. Narawong D, Gibbons VP, McLaughlin JR, et al: Conservative management of spinal epidural hematoma in haemophilia. Pediatr Neurol 1988; 4: 169-171.

21. Sheikh AA, Abildgaard CF: Medical management of extensive spinal epidural hematoma in a child with factor IX deficiency. Pediatr Emerg Care 1994; 10: 26-29.

22. Arieff AJ, Pyzik SW: Paraplegia following or associated with excessive dicumarol therapy. Q Bull Northw Univ Med Sch 1954; 284: 221-222.

23. Avrahami E, Tadmor R, Ram Z, et al: MR demonstration of spontaneous acute epidural hematoma of the thoracic spine. Neuroradiology 1989. 31: 89-92.

24. Bernsen PLJA, Haan J, Vielvoye GJ, et al: Spinal epidural hematoma visualized by magnetic resonance imaging. Neuroradiology 1988; 30: 280.

25. Pear BL: Spinal epidural hematoma. Am J Neuroradiol 1972; 155164. 